\title{
Perceived stigma toward mental health consumers does not influence willingness to seek mental health care nor psychiatry as a top residency choice among psychiatrically-minded 1st and 4th year medical students
}

\author{
Brent M. McGrath ${ }^{1}$ and Philip Tibbo ${ }^{2}$ \\ ${ }^{1}$ Class of 2010, Faculty of Medicine, Dalhousie University. \\ ${ }^{2}$ Bebensee Schizophrenia Research Unit, Department of Psychiatry, University of Alberta.
}

\begin{abstract}
Objective: The relationship between 1st and 4th year medical students' perceptions of mental illness stigma, their willingness to seek professional help for a mental health problem and their choice of psychiatry as a residency was assessed. Method: The survey was completed online, using well-established self-report inventories. Results: It appears that respondents with an interest in psychiatry have an accurate appraisal of the stigma experienced by those with a mental illness, and that this understanding develops independent of the knowledge and experience gained during their medical education. Perception of stigma had no influence on students' helpseeking orientation. Finally, medical students appear to develop an interest in psychiatry before their exposure to the specialty in the medical program. Conclusion: The stigma surrounding mental illness is not a barrier to seeking mental health care among this group of medical students. The results of the present study are discussed and evaluated in the context of the study's limitations.
\end{abstract}

Tn broad terms, stigma can be defined as the social-status loss and discrimination triggered by negative stereotypes that have become linked in a particular society to a particular human characteristic such as mental illness ${ }^{1}$. According to the World Psychiatric Association's 'Open the Doors' program, the stigma attached to mental illness and all that is related to it - patients who suffer from mental disorders, their families, psychiatric institutions, psychotropic medications - is the main obstacle to better mental health care and better quality of life ${ }^{2}$. Among those who stigmatize, this is often expressed in terms of being "unable to maintain a friendship", "disturbed about working on the same job", "afraid to have a conversation", and being unwilling to "marry" someone suffering from a mental illness, particularly schizophrenia ${ }^{3}$. For those with a mental illness, this often means reduced employment opportunities, difficulty in securing adequate housing, social status loss, poor interpersonal relationships, reduced self-esteem and social isolation ${ }^{4}$. Moreover, the stigma surrounding mental illness often negatively affects treatment adherence, only acting to increase the patient's illness burden, thus making stigma an important, pervasive, and damaging mental health comorbidity.

While there have been numerous studies assessing the impact of stigma on patients and their families, to date, there have been few studies investigating stigma from the perspective of physicians-in-training. This is a significant oversight given that research has shown that students entering medical school tend to possess more negative attitudes toward a career in psychiatry when compared with other specialties $^{5}$, the suicide rate among physicians is 1.1 to 3.4 times greater than that of the general population ${ }^{6}$, and that medical students'attitudes toward psychiatry and their experience with mental illness may influence residency choice. Moreover, there is evidence that psychiatrists themselves often contribute to the perpetuation of the stigma that surrounds mental illness and the mentally ill?

Given the above, the present manuscript reports results from a survey on the impact of stigma among a sample of fulltime first (Med-1) and fourth (Med-4) year medical students. These two groups were chosen in an effort to answer four questions: i. What are respondents' perceptions of the societal stigma toward mental illness and the mentally ill? ii. How willing are respondents to seek professional help for mental health problems? iii. What proportion of respondents rank psychiatry among their top residency choices? iv. Is there a relationship between stigma perception, help-seeking orientation, choice of psychiatry as a residency, and year of study among these respondents?

\section{Method \\ Sample}

All students enrolled in the first (Med-1; $\mathrm{N}=129$ ) and fourth (Med-4; $\mathrm{N}=126$ ) year of the Doctor of Medicine (MD) program at the University of Alberta were surveyed. The present study received approval from the Health Research Ethics Board and the Chair of Undergraduate Medical Education at the University of Alberta.

\section{Instruments}

To address the four questions above, two psychometrically 
validated self-report instruments were employed. Among them, the 10-item version of the Attitude Toward Seeking Professional Psychological Help Survey (ATSPPH) was used to determine help-seeking orientation. This instrument requires respondents to rate their level of agreement or disagreement with 10 statements about help-seeking for a mental health problem. Items are scored on a 4-point Likert-type scale ranging from "disagree" to "agree". Scores are summed across items to yield a total score that ranges from 0 to 30, with a scores higher then 15 indicative of a more pro-help-seeking orientation, and those below 15 of a anti-help-seeking orientation. The original version of this instrument was developed and tested in a large population of students and was shown to possess good internal reliability $(\mathrm{a}=0.86)$ as well as test-retest reliability $(\mathrm{r}=0.89)^{8}$. The ATSPPH has been validated and utilized by numerous research groups. The Devaluation-Discrimination Scale (DDS) was utilized to measure respondents' perceptions of societal stigma surrounding mental illness and the mentally ill. This instrument was originally designed to assess the extent to which respondents believe that "most people" will devalue or discriminate against a person with a history of psychiatric treatment. Respondents are asked to rate their level of agreement or disagreement with 12 statements about what most people think. Items are rated on a 4-point Likert-type scale ranging from "strongly disagree" to "strongly agree". The instrument is scored by either summing across all items to achieve a total score and/or by summing across all items and dividing by the number of answered items (usually 12) to achieve a mean score. The resultant mean score is then compared to the 2.5 midpoint, with a high score indicative of a high level of perceived devaluation-discrimination. Previous studies in patients have shown this instrument to possess good internal reliability $(a=0.82)^{9}$. Students were also asked if psychiatry was among their top residency choices.

\section{Survey}

Students were sent an electronic e-mail explaining the study and providing a link to the online survey. Students were also informed that the survey was anonymous. Students who wished to take part were instructed to complete the survey by way of the link, with survey completion taken as consent. Groups were compared using the independent samples t-test and the single sample t-test for continuous variables and the Pearson's Chi-squared test for categorical variables. Pearson product moment correlation was used to investigate relationships between variables. Statistical significance was evaluated at the 0.05 alpha level.

\section{Results}

From the 255 Medical students enrolled in first and fourth year at the University of Alberta, 85 (46 Med-1 and 39 Med-4) completed the online survey, for a response rate of $33 \%$. The two groups of respondents did not differ significantly on response rates $(\mathrm{t}=-0.795,253 \mathrm{df}, \mathrm{p}=0.427)$.
All demographic characteristics for Med-1 and Med4 respondents are reported, across genders, in Table 1.

\section{Help-Seeking Orientation (ATSPPH)}

Among all respondents, the mean total score was 17.78 $(\mathrm{SD}=5.52)$, which was significantly above the midpoint of 15 (i.e. a neutral attitude) $(\mathrm{t}=4.49,79 \mathrm{df}, \mathrm{p}<0.01)$ (Table 2).

\begin{tabular}{|c|c|c|c|c|c|}
\hline & \multicolumn{2}{|c|}{$\begin{array}{l}\text { Med-1 } \\
(n=46)^{1}\end{array}$} & \multicolumn{2}{|c|}{$\begin{array}{l}\text { Med-4 } \\
(n=39)\end{array}$} & \multirow{2}{*}{\begin{tabular}{|l} 
Significance $^{2}$ \\
$p=0.330$
\end{tabular}} \\
\hline & $\begin{array}{c}\text { Males } \\
(16)\end{array}$ & $\begin{array}{c}\text { Females } \\
\text { (29) }\end{array}$ & $\begin{array}{c}\text { Males } \\
\text { (18) }\end{array}$ & $\begin{array}{c}\text { Females } \\
\text { (21) }\end{array}$ & \\
\hline \multicolumn{6}{|c|}{ DEMOGRAPHIC } \\
\hline \multicolumn{6}{|l|}{$\mathrm{Age}^{3}$} \\
\hline Mean(SD) & $23(3)$ & $22(2)$ & $25(2)$ & $25(2)$ & $p<0.0001$ \\
\hline$<20$ years & 0 & 0 & 0 & 0 & $p=0.179$ \\
\hline 20-25 years & $\begin{array}{l}12 \\
(75.0 \%)\end{array}$ & $\begin{array}{l}25 \\
(86.2 \%) \\
\end{array}$ & $\begin{array}{l}11 \\
(61.1 \%)\end{array}$ & $\begin{array}{l}15 \\
(71.4 \%)\end{array}$ & \\
\hline $26-30$ years & $\begin{array}{l}3 \\
(18.8 \%)\end{array}$ & $\begin{array}{l}3 \\
(10.3 \%)\end{array}$ & $\begin{array}{l}6 \\
(33.3 \%)\end{array}$ & $\begin{array}{l}5 \\
(23.8 \%)\end{array}$ & \\
\hline$>30$ years & 0 & \begin{tabular}{|l|}
1 \\
$(3.4 \%)$
\end{tabular} & $\begin{array}{l}1 \\
(5.6 \%)\end{array}$ & $\begin{array}{l}1 \\
(4.8 \%)\end{array}$ & \\
\hline
\end{tabular}

Living

Situation

\begin{tabular}{|l|l|l|l|l|l|}
\hline House & $\begin{array}{l}7 \\
(43.8 \%)\end{array}$ & $\begin{array}{l}14 \\
(48.3 \%)\end{array}$ & $\begin{array}{l}11 \\
(61.1 \%)\end{array}$ & $\begin{array}{l}8 \\
(38.1 \%)\end{array}$ & $p=0.744$ \\
\hline Apartment & $\begin{array}{l}9 \\
(56.3 \%)\end{array}$ & $\begin{array}{l}14 \\
(48.3 \%)\end{array}$ & $\begin{array}{l}5 \\
(27.8 \%)\end{array}$ & $\begin{array}{l}13 \\
(61.9 \%)\end{array}$ & \\
\hline Condo & 0 & $\begin{array}{l}3 \\
(10.3 \%)\end{array}$ & $\begin{array}{l}2 \\
(11.1 \%)\end{array}$ & 0 & \\
& & & & \\
\hline
\end{tabular}

Living Status

\begin{tabular}{|l|l|l|l|l|l|}
\hline $\begin{array}{l}\text { With family/ } \\
\text { children }\end{array}$ & $\begin{array}{l}7 \\
(43.8 \%)\end{array}$ & $\begin{array}{l}12 \\
(41.4 \%)\end{array}$ & $\begin{array}{l}9 \\
(50.0 \%)\end{array}$ & $\begin{array}{l}6 \\
(28.6 \%)\end{array}$ & $p=0.507$ \\
\hline With friend & $\begin{array}{l}2 \\
(12.5 \%)\end{array}$ & $\begin{array}{l}4 \\
(13.8 \%)\end{array}$ & $\begin{array}{l}2 \\
(11.1 \%)\end{array}$ & $\begin{array}{l}8 \\
(38.1 \%)\end{array}$ & \\
\hline Lives alone & $\begin{array}{l}4 \\
(25 \%)\end{array}$ & $\begin{array}{l}10 \\
(34.5 \%)\end{array}$ & $\begin{array}{l}5 \\
(27.8 \%)\end{array}$ & $\begin{array}{l}4 \\
(19.0 \%)\end{array}$ & \\
\hline With spouse & $\begin{array}{l}3 \\
(18.8 \%)\end{array}$ & $\begin{array}{l}3 \\
(10.3 \%)\end{array}$ & $\begin{array}{l}2 \\
(11.1 \%)\end{array}$ & $\begin{array}{l}3 \\
(14.3 \%)\end{array}$ & \\
\hline
\end{tabular}

Marital

Status

\begin{tabular}{|c|c|c|c|c|c|}
\hline Single & $\begin{array}{l}13 \\
(81.3 \% \\
\end{array}$ & $\begin{array}{l}26 \\
(89.7 \%)\end{array}$ & $\begin{array}{l}13 \\
(72.2 \%)\end{array}$ & $\begin{array}{l}17 \\
(81.0 \%)\end{array}$ & $p=0.127$ \\
\hline Married & $\begin{array}{l}2 \\
(12.5 \%)\end{array}$ & $\begin{array}{l}1 \\
(3.4 \%)\end{array}$ & $\begin{array}{l}5 \\
(27.8 \%)\end{array}$ & $\begin{array}{l}3 \\
(14.3 \%)\end{array}$ & \\
\hline Dating & 0 & 0 & 0 & $\begin{array}{l}1 \\
(4.8 \%) \\
\end{array}$ & \\
\hline Common Law & 0 & $\begin{array}{l}2 \\
(6.9 \%)\end{array}$ & 0 & 0 & \\
\hline Divorced & $\begin{array}{l}1 \\
(6.3 \%)\end{array}$ & 0 & 0 & 0 & \\
\hline \multicolumn{6}{|l|}{ ACADEMIC } \\
\hline \multicolumn{6}{|c|}{$\begin{array}{l}\text { Is psychiatry among your top choices for a } \\
\text { residency? }\end{array}$} \\
\hline Yes & $\begin{array}{l}2 \\
(12.5 \%)\end{array}$ & $\begin{array}{l}10 \\
(34.5 \%)\end{array}$ & $\begin{array}{l}3 \\
(16.7 \%)\end{array}$ & $\begin{array}{l}4 \\
(19.0 \%)\end{array}$ & $p=0.264$ \\
\hline No & $\begin{array}{l}14 \\
(87.5 \%)\end{array}$ & $\begin{array}{l}19 \\
(65.5 \%)\end{array}$ & $\begin{array}{l}15 \\
(83.3 \%)\end{array}$ & $\begin{array}{l}17 \\
(81.0 \%)\end{array}$ & \\
\hline
\end{tabular}

${ }^{1}$ Gender data missing for one respondent.

${ }^{2}$ Med-1 versus Med-4; Independent Samples t-test was used for continuous variables and Pearson Chi-square test for categorical variables.

${ }^{3}$ Data missing for one male Med-1 respondent. 


Table 2. Med-1 and Med-4 respondents' scores on the ATSPPH and the DDS inventories
\begin{tabular}{|l|l|l|l|l|}
\hline \multicolumn{1}{|c|}{ Total Score } & \multicolumn{1}{|c|}{ All M (SD) } & \multicolumn{1}{|c|}{ Med-1 M (SD) } & \multicolumn{1}{c|}{ Med-4 M (SD) } & \multicolumn{1}{|c|}{ Significance $^{1}$} \\
\hline $\begin{array}{l}\text { ATSPPH Summed Total } \\
\text { Score }^{2}\end{array}$ & $17.78^{5}(5.52)$ & $17.74^{5}(5.03)$ & $17.82^{5}(6.09)$ & $\mathrm{p}=0.950$ \\
\hline $\begin{array}{l}\text { DDS Summed Total } \\
\text { Score }^{3}\end{array}$ & $32.85(4.64)$ & $32.51(4.92)$ & $33.21(4.34)$ & $\mathrm{p}=0.507$ \\
\hline DDS Mean Total Score & & & & \\
\hline
\end{tabular}

ATSPPH; Attitude Toward Seeking Professional Psychological Help Scale

DDS; Devaluation - Discrimination Scale

${ }^{1}$ Med-1 versus Med-4, Independent Samples t-test was used for continuous variables and Pearson Chi-square for categorical variables.

${ }^{2}$ Data missing for 5 respondents (4 Med-1 and 1 Med-4)

Data missing for 6 respondents ( 5 Med-1 and 1 Med-4)
Data missing for 4 respondents ( 3 Med- 1 and 1 Med-4)

${ }^{5}$ Significantly greater than the midpoint value of $15(p<0.01)$

${ }^{6}$ Significantly greater than the midpoint value of $2.5(p<0.01)$

No difference was found between Med-1 and Med4 respondents on mean total score $(\mathrm{t}=-0.062,78 \mathrm{df}$, $\mathrm{p}=0.950$ ) and both groups expressed a significantly positive attitude toward mental health help-seeking (Med-1: $\mathrm{t}=3.53,41 \mathrm{df}, \mathrm{p}<0.01$ and Med-4: $\mathrm{t}=2.85,37 \mathrm{df}, \mathrm{p}<0.01)$.

\section{Perceptions of Societal Stigma (DSS)}

Among all respondents, the average total score was 32.85 $(\mathrm{SD}=4.64)$, with a mean total score of $2.73(\mathrm{SD}=0.39)$ (Table 2). The mean total score for all respondents was significantly higher than the 2.5 midpoint $(t=5.20,80 \mathrm{df}$, $\mathrm{p}<0.01$ ), indicating that most respondents perceived a

Table 3. Correlations between demographic, academic, and
attitudinal variables among Med-1 and Med-4 respondents.
\begin{tabular}{|l|l|l|l|l|}
\hline Variables & $\begin{array}{c}\text { Residency } \\
\text { Choice }\end{array}$ & $\begin{array}{c}\text { ATSPPH } \\
\text { Total } \\
\text { Score }\end{array}$ & $\begin{array}{l}\text { DDS Total } \\
\text { Score }\end{array}$ & $\begin{array}{l}\text { DDS Mean } \\
\text { Score }\end{array}$ \\
\hline Med-1 Respondents \\
\hline Gender & -0.238 & 0.255 & 0.229 & 0.263 \\
\hline Age & -0.080 & 0.096 & 0.230 & 0.203 \\
\hline $\begin{array}{l}\text { Residency } \\
\text { Choice }\end{array}$ & --- & -0.142 & -0.127 & -0.054 \\
\hline $\begin{array}{l}\text { ATSPPH } \\
\text { Total } \\
\text { Score }\end{array}$ & -0.072 & --- & 0.206 & 0.187 \\
\hline $\begin{array}{l}\text { DDS Total } \\
\text { Score }\end{array}$ & -0.127 & 0.206 & --- & --- \\
\hline $\begin{array}{l}\text { DDS Mean } \\
\text { Score }\end{array}$ & -0.054 & 0.187 & --- & --- \\
\hline Med-4 Respondents & & $-0.492^{2}$ & -0.018 & -0.018 \\
\hline Gender & -0.031 & -0.235 & 0.217 & 0.217 \\
\hline Age & 0.170 & $-0.365^{1}$ & 0.023 & 0.023 \\
\hline $\begin{array}{l}\text { Residency } \\
\text { Choice }\end{array}$ & --- & --- & -0.279 & -0.279 \\
\hline $\begin{array}{l}\text { ASTPPH } \\
\text { Total } \\
\text { Score }\end{array}$ & $-0.365^{1}$ & --279 & --- & --- \\
\hline $\begin{array}{l}\text { DDS Total } \\
\text { Score }\end{array}$ & 0.023 & -0.279 & --- & --- \\
\hline $\begin{array}{l}\text { DDS Mean } \\
\text { Score }\end{array}$ & 0.023 & -0.23 & \\
\hline
\end{tabular}

Pearson Product Moment Correlation: ${ }^{1} p<0.05 ;{ }^{2} p<0.005$ high level of societal devaluation and discrimination di rected toward persons with mental illness. No difference was found between Med-1 and Med-4 respodents on average total score $(\mathrm{t}=-0.666,77 \mathrm{df}, \mathrm{p}=0.507)$ or average mean total score $(\mathrm{t}=-0.898,79 \mathrm{df}, \mathrm{p}=0.372)$. However, both groups scored significantly higher than the 2.5 midpoint (Med-1: $\mathrm{t}=2.99,42 \mathrm{df}, \mathrm{p}<0.01$ and Med-4: $\mathrm{t}=4.56,37 \mathrm{df}, \mathrm{p}<0.01$ ).

\section{Residency Preference}

Among respondents, 12 (26\%) Med-1 and 7 (18\%) Med-4 indicated that psychiatry was among their top choices for a residency program (Table 1). There was no significant difference between Med-1 and Med-4 respondents with regards to their indication of psychiatry as a top residency choice $\left(\mathrm{x}^{2}=1.25,1 \mathrm{df}, \mathrm{p}=0.264\right)$.

\section{Cross Correlations}

Interestingly, among Med-4 respondents, those who indicated that psychiatry was among their top residency choices were significantly more pro-help-seeking $(r=-0.365$, $\mathrm{p}<0.05)$, with psychiatry as a top choice of residency accounting for more than $13 \%\left(r^{2}=0.133\right)$ of the variance in help-seeking scores (Table 3). Among Med-4 respondents, gender was positively correlated with mean total ATSPPH score, where being female was predictive of a pro-help-seeking orientation $(r=0.492, p<0.005)$, accounting for $24 \%\left(r^{2}=0.242\right)$ of the variance in help-seeking scores. Finally, among Med-1 and Med-4 respondents, perception of stigma did not correlate with their mental health help-seeking orientation.

\section{Discussion}

According to the World Psychiatric Association's Open the Doors anti-stigma program, the stigma attached to mental illness and psychiatry, and the resulting discrimination of people with mental disorders are major obstacles to early and successful treatment ${ }^{11}$. While much work has been done to quantify the effect of stigma on those with a mental illness, few have studied stigma and its effects from other perspectives. The present study aimed at closing this gap. Inferences made from the present study must be measured against two important study limitations. First, the response rate, while comparable with similar studies, may not allow 
for an accurate estimation of the attitudes of the population of medical students as a whole. Second, and related to the first, a large minority of respondents indicated that psychiatry was among their top choices for residency. This rate is higher than the actual rate reported by the Canadian Resident Matching Service (CaRMS), where in 2003, 5.8\% of medical graduates from the University of Alberta ranked psychiatry as their first choice*. Given this, the findings in the present study will be framed as applying to a population of medical students who have an above average interest in psychiatry.

\section{Help-Seeking Orientation (ATSPPH)}

Contrary to the findings of Chew-Graham and colleagues in a general student population ${ }^{12}$, respondents with a strong interest in psychiatry reported a pro-help-seeking orientation, across both the Med-1 and Med-4 groups. This finding is important, particularly in light of the stresses experienced in medical school and the elevated risk, as a function of age and occupational choice for mental illness in this demographic ${ }^{13,14}$.

\section{Perceptions of Societal Stigma (DSS)}

Among respondents with a strong interest in psychiatry, there is an accurate appraisal of the stigma experienced by those with a mental illness. This appreciation appears to develop independent of the knowledge and experience gained during their medicaleducation or psychiatry clerkship, evidenced by the lack of a difference between Med1 and Med-4 students on this measure. Moreover, these perceptions were similar to those of a non-medical student population (unpublished data), and are similar to results from studies that have evaluated how patients themselves perceive the stigma that surrounds mental illness ${ }^{4,15}$.

\section{Residency Preference}

Both Med-1 and Med-4 respondents did not differ on their indication of psychiatry as their top residency choice. In this way, the quality of the exposure to psychiatry in the later years of the medical program may not be the most influential factor in a students choice of this residency program, but rather, their perceptions upon entering the medical program may be more important. The numbers of students indicating that psychiatry was among their top choices was higher then previous reports, and may be the result of a response bias. Interestingly, a recent study of Malaysian medical students reported an increase in positive attitudes toward mental illness and toward psychiatry among female students but not among male students, following an 8-week clinical rotation ${ }^{16}$. These findings warrant further, longitudinal study.

\section{Limitations}

While the findings of the present study are important, any inferences made must be measured against the study's limitations. Firstly, the present study was a cross-sectional survey, preventing the tracking of perceptions and attitudes over

\footnotetext{
$*_{\text {http://www.carms.ca/jsp/main.jsp?path=../content/statistics/report/re_2003\#table31 }}$
}

time, as well as the relationship between these attitudes and future behaviour. Secondly, the response rate, while comparable with similar studies, may not allow for an accurate estimation of the attitudes of the population as a whole. However, it is felt that the method of survey administration (i.e. by email) provided the greatest likelihood of response, given that respondents could complete it when and where they desired. Interestingly, this result is similar to that found in a larger sample $(n=300)$ of non-medical students at the same university ${ }^{17}$. Furthermore, it appears that respondents are more psychiatrically-minded than are most medical students. Thirdly, self-report data may be biased due to social desirability. It is also important to note that attitude is only one aspect influencing help-seeking behaviour and may not be predictive of future actions. Finally, the present study did not control for whether or not the respondents themselves suffered from a mental illness.

\section{Conclusion}

To the author's knowledge, this is the first study to assess the relationship between a medical students perception of stigma and their willingness to seek help for a mental health problem. At the University of Alberta, similar to here at Dalhousie, exposure to psychiatry in the medical curriculum usually begins during clerkship in year three. Interestingly, although Med-4 respondents had significantly more" exposure to mental illness - typically in relation to their program of study - than did Med-1 respondents, both groups had similarly negative perceptions of what "most people" think about persons with a mental illness. Moreover, these perceptions were similar to those of a non-medical student population ${ }^{17}$, and similar to results that have evaluated how patients themselves perceive the attitudes of "most people" toward persons with a mental illness ${ }^{4,15}$. Among such patients, high levels of devaluation and discrimination have been linked to their level of income and employment ${ }^{15}$, quality of life $^{4}$ and self-esteem ${ }^{4}$. From the above, it appears that these medical students have an accurate appraisal of the stigma experienced by those with a mental illness, and that this understanding develops independent of the knowledge and experience gained during their medical education. Although aware of the negative consequence of being labeled mentally ill, these medical students still indicated a willingness to seek treatment for mental health problems if they develop. Furthermore, it appears that the stigma surrounding mental illness does not negatively influence the choice of psychiatry as a residency. However, it appears that respondents are more psychiatrically-minded than are most medical students. For the majority of medical students, formal psychiatric education in the medical curriculum typically begins during clerkship. Given the prevalence of psychiatric disorders in the population, an argument can easily be made for earlier and increased exposure to this specialty. However, in an increasingly specializing field such as medicine, it is 
difficult to see how this could be done, without compromising exposure to other specialties. From the present study, it appears that - at least in the case of psychiatrically-minded students - interest in psychiatry may develop before exposure in the medical curriculum. In general, more research is needed regarding student's choice of residency programs.

\section{ACKNOWLEDGEMENTS}

The authors would like to acknowledge the personnel at both the University of Alberta's Office of External Relations' Creative Services department for their assistance in developing and implementing the online survey, and the Office of the Registrar and Student Awards for their assistance in population sampling and survey distribution. The Bebensee Schizophrenia Research Unit of the Department of Psychiatry at the University of Alberta provided funding for this study. This study was presented, in part, at the 55th Annual meeting of the Canadian Psychiatric Association and the annual meeting of the Association for Academic Psychiatry.

\section{REFERENCES}

1. Link BG, Phelan JC. Conceptualizing stigma. Annu Rev Sociol 2001;27:363385.

2. Sartorius N, Schulze H. Reducing the stigma of mental illness. A report from a global programme of the World Psychiatric Association. Cambridge: Cam bridge University Press, 2005:1-264.

3. Gaebel W, Baumann AE. Interventions to reduce the stigma associated with severe mental illness: Experiences from the open the doors program in Ger many. Can J Psychiatry 2003;48:657-662.

4. Link BG, Struening EL, Neese-Todd S, Asmussen S, Phelan JC. Stigma as a barrier to recovery: The consequences of stigma for the self-esteem of people with mental illnesses. Psychiatr Serv 2001;52(12):621-626.

5. Feifel D, Moutier CY, Swerdlow NR. Attitudes toward psychiatry as a prospective career among students entering medical school. Am J Psychiatry 1999;156:1397-1402.
6. Lindeman S, Laara E, Hakko H, Lonnqvist J. A systematic review on genderspecific suicide mortality in medical doctors. Br J Psychiatry 1996;168(3): $274-279$

7. Bar-Levav R. The stigma of seeing a psychiatrist. Am J Psychotherapy 1976;30(3):473-482.

8. Fischer EH, Farina A. Attitudes towards seeking professional psychological help: A shortened form and considerations for research. J College Stud Devel 1995;36(4):368-373.

9. Link BG, Mirotznik J, Cullen FT. The effectiveness of stigma coping orientations: Can negative consequences of mental illness labeling be avoided? J Health Soc Behav 1991;32:302-320.

10. Struening EL, Perlick DA, Link BG, Hellman F, Herman D, Sirey JA. The extent to which caregivers believe most people devalue consumers and their families? Psychiatr Serv 2001;52(12):1633-1638.

11. Gaebel W, Baumann AE. "Open the doors" - the antistigma program of the World Psychiatric Association. MMW Fortschr Med 2003;145(12):34-37.

12. Chew-Graham CA, Rogers A, Yassin N. 'I woundn't want it on my CV or their records': Medical students' experiences of help-seeking for mental health problems. Med Educ 2003;37:873-880.

13. Roberts LW, Warner TD, Trumpower D. Caring for medical students as patients: Access to services and care-seeking practices of 1027 students at non-medical schools. Collaborative Research Group on Medical Student Healthcare. Acad Med 2000;75(3):272-277.

14. Firth-Cozens J. The stresses of medical training, in Stress in Health Professionals. Edited by Payne R, Firth-Cozens J. Chicester, Wiley, 1987.

15. Link BG. Understanding labeling effects in the area of mental disorders: An assessment of the effects of expectations of rejection. Am Sociol Rev 1987;52(1):96-112.

16. Reddy JP, Tan SM, Azmi MT, Shaharom MH, Rosdinom R, Maniam T, Ruzanna ZZ, Minas IH. The effect of a clinical posting in psychiatry on the attitudes of medical students towards psychiatry and mental illness in a Malaysian medical school. Ann Acad Med Singapore 2005;34(8):505-510.

17. Tibbo P \& McGrath BM. University Students Perceptions of the Stigma toward Mental Health Consumers and their Families: Does Perception of Stigma influence Willingness to Seek Help for Mental Health Problems? 55th Annual Meeting of the Canadian Psychiatric Association. Theme: Building Networks, Crafting Excellence. Vancouver, Canada, November 2005.

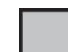 FINANCIAL ADVICE \\ World Class. Physician Focused.
}

\author{
Advice and service to achieve your goals. \\ Don't leave RRSP and RESP contributions to the last minute. \\ Whether starting your career, planning for your children's future, or \\ looking for ways to minimize your taxes, early and regular contributions \\ to RRSPs and RESPs are an important part of your overall retirement plan. \\ Pre-authorized contributions arranged with your MD representative are \\ a fast and easy way to start.
}

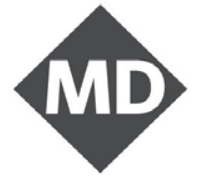

FINANCIAL

CMA COMPANIES Benefit from disciplined, long-term investing. Remember, you can't buy back time.

Contact MD Financial today. mdfinancial.cma.ca $\triangle 1800$ 565-1771

\footnotetext{
MD Financial includes CMA Holdings Incorporated companies offering financial planning and a banking referral service through MD Management Limited, mutual funds by MD Funds Management Inc. and MD Private Trust Company, investment counselling services by MD Private Investment Management Inc., estate and trustee services ${ }^{*}$ by MD Private Trust Company and insurance products by MD Life Insurance Company and MD Insurance Agency Limited.

*In Québec, liquidator and trustee services.
} 